\title{
The Agnostic's Response to Climate Deniers: Price Carbon!*
}

\author{
Frederick van der Ploeg, University of Oxford ${ }^{\dagger}$ \\ Armon Rezai, WU and IIASA
}

\begin{abstract}
With the election of President Trump, climate deniers feel emboldened and moved from the fringes to the centre of global policy making. We study how an agnostic approach to policy, based on Pascal's wager and allowing for subjective prior probability beliefs about whether climate deniers are right, prices carbon. Using the DICE integrated assessment model, we find that assigning a $10 \%$ chance of climate deniers being correct lowers the global price on carbon in 2020 only marginally: from $\$ 21$ to $\$ 19$ per ton of carbon dioxide if policymakers apply 'Nordhaus discounting' and from $\$ 91$ to $\$ 84$ per ton of carbon dioxide if they apply 'Stern discounting'. Agnostics' reflection of remaining scientific uncertainty leaves climate policy essentially unchanged. The robustness of an ambitious climate policy also follows from using the max-min or the min-max regret principle. Letting the coefficient of relative ambiguity aversion vary from zero, corresponding to expected utility analysis, to infinity, corresponding to the max-min principle, we show how policy makers deal with fundamental climate model uncertainty if they are prepared to assign prior probabilities to different views of the world being correct. Allowing for an ethical discount rate and a higher market discount rate and for a wide range of sensitivity exercises including damage uncertainty, we show that pricing carbon is the robust response under rising climate scepticism.
\end{abstract}

Keywords: climate model uncertainty, differential discount rates, climate scepticism, robust climate policies, max-min, min-max regret, ambiguity aversion, DICE integrated assessment model

JEL codes: H21, Q51, Q54

Revised July 2018

\footnotetext{
${ }^{*}$ Rezai acknowledges support from Austrian Science Fund (J3633). Van der Ploeg acknowledges support from the BP funded Oxford Centre for the Analysis of Resource Rich Economies. We thank Henk Dijkstra, Cameron Hepburn, Antony Millner, Nicholas Stern, Joe Stiglitz, Tony Venables, Sweder van Wijnbergen, and Tim Willems for helpful comments and discussions on the topic of climate skepticism and fundamental climate uncertainty. We are also grateful to two anonymous referees for their constructive comments and suggestions.

${ }^{\dagger}$ Department of Economics, Oxford University, Manor Road Building, Manor Road, Oxford OX1 3UQ, U.K. Also affiliated with VU University Amsterdam, CEPR and CESifo. Email address: rick.vanderploeg@economics.ox.ac.uk. * Department of Socioeconomics, WU - Vienna University of Economics and Business, Welthandelsplatz 1, 1020 Vienna, Austria. Also affiliated with IIASA. Email address: armon.rezai@wu.ac.at.
} 


\section{Introduction}

There is widespread consensus among climate scientists and economists that carbon emissions should be priced to avoid global warming and the associated economic costs. Nordhaus (2014) arrives at a price of $\$ 21$ per ton of carbon dioxide (CO2) in 2020 and peak warming of $3.3^{\circ} \mathrm{C}$ using the DICE2013-R integrated assessment model. This price is viewed by many as much too low and seems at variance with much of the science and the internationally agreed objective of keeping temperature below $2^{\circ} \mathrm{C}$ or even $1.5^{\circ} \mathrm{C}$. Nordhaus (2018) acknowledges that it is unlikely that countries will meet the Paris target of $2^{\circ} \mathrm{C}$ even if climate policy is stepped up in the near term. Nordhaus (2018) also argues that the required carbon price has risen due to the delay in policy implementation in accordance with the arguments made earlier by Stern (2018). We find that the carbon price changes from $\$ 21 / \mathrm{tCO} 2$ to $\$ 91 / \mathrm{tCO} 2$ and peak warming to $2^{\circ} \mathrm{C}$ if policy makers take a farsighted ethical stance as discussed in detail in Stern (2015) and Gollier (2018), and use the low social discount rates proposed in Stern (2007) while private agents are still using the high market-based discount rates of Nordhaus (2014). ${ }^{1}$ Inclusion of the various economic, climate and damage risks and the risks of tipping points will push up the optimal carbon price much higher still. ${ }^{2}$ Furthermore, the optimal carbon price is pushed up if there are strong nonlinearities in the damage function, i.e., if marginal damages of emitting carbon rise with the degree of global warming (e.g., Ackerman and Stanton, 2012; Dietz and Stern, 2014; Rezai and van der Ploeg, 2016). ${ }^{3}$

\footnotetext{
${ }^{1}$ Arrow et al. (1996) distinguished the prescriptive approach with the rate of pure time preference set to zero and the social discount rate somewhere between $0.5 \%$ and $3 \%$ per year (for an elasticity of intertemporal substitution and of trend growth of per-capita GDP of 1 and $0.5 \%$, and 0.5 and $1.5 \%$, respectively) from the descriptive approach with the social discount rate derived from the higher market return on investments (say, 3-6\% per year, not allowing for risk). The choices for the social discount rate used in Nordhaus (2014) and Stern (2007) seem to correspond to the descriptive and prescriptive approaches, respectively.

${ }^{2}$ The price of carbon is pushed up significantly if account is taken of various kinds of economic, climate and damage uncertainties (Crost and Traeger, 2014; Jensen and Traeger, 2014; Bansal et al., 2016; Hambel et al., 2017; van den Bremer and van der Ploeg, 2018) or of the risk of (multiple) tipping points (e.g., van der Ploeg, 2014; Lontzek et al., 2014; Cai et al., 2016; Lemoine and Traeger, 2016; van der Ploeg and de Zeeuw, 2018). Nordhaus (2017) also indicates that carbon prices can be much higher with lower discount rates and stresses the importance of damage uncertainties. Finally, Weitzman (2009) show how the effects of fat-tailed structural uncertainty on the economics of lowprobability, high-impact catastrophes (combined with uncertainty about high-temperature damages) can outweigh the effects of discounting on the price of carbon, so that this price becomes infinite. This has been coined the Dismal Theorem.

${ }^{3}$ In fact, convexities of the damage function can amplify the effects of stochastic shocks on the price of carbon (e.g., van den Bremer and van der Ploeg, 2018). Furthermore, waiting with taking ambitious climate action then leads to a much higher costs of climate policy (cf. Stern, 2015).
} 
Despite these high welfare-maximising values for the carbon price, the notion that anthropogenic emissions cause global warming and consequently the message that pricing carbon curbs global warming is doubted by many citizens, business people, and politicians (perhaps due to lack of scientific understanding of the inevitable processes underlying global warming, vested fossil fuel interests, or both). Of course, whether society is able to do anything about global warming depends on whether society is causing it. Hence, if anthropogenic carbon emissions are not the cause of global warming, then reducing emissions are unlikely to be the solution. This is why climate sceptics are against pricing carbon emissions.

The many ways by which pricing carbon reduces global warming, viz. curbing demand for fossil fuel, switching from CO2-intensive coal to less intensive gas, encouraging renewable energy production and green $R \& D$, stimulating insulation, carbon capture \& sequestration, locking up coal, oil and gas in the crust of the earth, et cetera, may also not be fully understood, wilfully or not. Our objective is to take the views of climate deniers at face value and investigate their effects on the derivation of optimal climate policy if this is based on their views as well as those of the views in the climate science community. We investigate what decision theory says about how to deal with different views on global warming and their costs. We thus adopt an agnostic approach to policy where the scientific uncertainty that climate deniers could be right after all is scientifically accounted for. ${ }^{4}$ To keep matters as clear as possible, we focus at fundamental climate model uncertainty only and abstract from all other forms of statistical uncertainties of economic growth, climate, and damage and the risk of tipping points.

In the seventeenth century, the French philosopher Blaise Pascal pioneered decision making under such fundamental model uncertainty by asking if one should believe in (the Christian) God on the understanding that one cannot derive from reason whether God exists (Pascal, 1670). Pascal's recommendation for agnostics was assertive: believe in God, if you hold only the slightest prior belief that God could exist. The rationale is that the cost of wrongly believing in God is minimal or at least finite, but the cost of wrongly not believing is infinite (eternal damnation and burning in a Lake of Fire) and/or the benefit of rightly believing in God infinite (eternal bliss in Paradise).

\footnotetext{
${ }^{4}$ It is important to be clear about terminology: climate deniers are $100 \%$ certain that global warming has only natural causes whereas climate believers (or non-sceptic scientists) are $100 \%$ certain that anthropogenic carbon emissions contribute to global warming. Climate sceptics or agnostics attach a small positive probability that climate deniers are right or at least acknowledge the possibility that global warming is not caused by anthropogenic carbon emissions at all. In political debate, however, climate deniers are sometimes euphemistically referred to as "climate sceptics".
} 
We adopt similar reasoning to argue that climate agnostics, who cannot fully discount the position that science has got it all wrong, should push for stringent climate policy nonetheless. We argue that acknowledgment of scientific uncertainty about our understanding of climate change in the pursuit of robust climate policies under epistemological uncertainty about what the right climate model and what the right damage function are leads to only minimal downward revision of optimal mitigation efforts.

The appointment by President Trump of an outspoken climate sceptic at the top of the Environmental Protection Agency in the United States has thrown global climate policy in the ropes. ${ }^{5}$ While genuine climate deniers are not swayed by doubt, prudent science must deal with the error that a model is falsely assumed to be correct. For this purpose, we draw on a variety of decision-theoretic approaches. The first one is expected-utility analysis with a subjective probability of climate deniers being correct. If such a climate policy does not differ very much from the one advocated by climate scientists, even with relatively high probabilities of climate deniers being right, an agnostic policy maker should pursue an ambitious climate policy nevertheless. The second one is the max-min approach, which delivers a robust climate policy by doing the best one can do under the worst possible model of the climate and of damages (Wald, 1945; Gilboa and Schmeidler, 1989). ${ }^{6}$ Since the welfare losses from not fighting global warming if anthropogenic global warming is correct are relatively large (due to relatively high damages at 4 to 7 or more degrees Celsius) whilst those from fighting global warming when climate deniers are correct are relatively small (the welfare cost of distorting taxes on emissions minus the welfare gains from rebates), the max-min optimal policy is to price carbon. The third approach is the minmax-regret approach, which also delivers a robust climate policy by minimising the regret of pursuing the wrong policy under the worst possible outcome (Savage, 1954). The final approach is based on the more modern approach of relative ambiguity aversion, denoted by $A A$, and allows for a continuum between expected utility analysis where $A A=0$ and max-min analysis where $A A \rightarrow \infty$ (Klibanoff et al., 2005).

\footnotetext{
${ }^{5}$ Only on March 9, 2017, Scott Pruitt, head of the US EPA, stated "[...] I think that measuring with precision human activity on the climate is something very challenging to do and there's tremendous disagreement about the degree of impact. So no, I would not agree that it's a primary contributor to the global warming that we see." The Trump administration's first budget proposal cut funding for the EPA by $31 \%$.

${ }^{6}$ Gilboa and Schmeidler (1989) give an axiomatic foundation of the max-min principle using the axiom of uncertainty aversion, the axiom of certainty independence (or the sure thing principle which weakens the classical independence axiom) as well as the usual axioms of transitivity, completeness, continuity and monotonicity.
} 
We use a modular approach to optimal climate policy formulation (NAS, 2017; Rezai and van der Ploeg, 2018a). We have a common model of the economy, which for simplicity we take to be the DICE integrated assessment model (Nordhaus, 2008, 2013). We distinguish two models of the climate: one based on the carbon and temperature model of DICE and a modified one to capture the view of climate deniers. We also consider a sensitivity exercise where we distinguish two types of damage functions from global warming: the DICE damages with relatively flat marginal damages and a variant with more convex damages (e.g., Weitzman, 2010; Dietz and Stern, 2015). We then consider each of the four decision-theoretic approaches to see how much climate policies are affected by taking the view of climate deniers at face value. We conclude that even when giving (a lot of) credence to climate deniers policy makers should price carbon almost as high as in the absence of climate deniers.

Rezai and van der Ploeg (2018b) deal with similar issues. The novelty of this paper is fourfold: (i) we allow for both climate model uncertainty and damage specification uncertainty and thus speak to the modular approach of NAS (2017); (ii) we allow for ambiguity aversion thereby nesting expected utility and max-min outcomes in a continuum; (iii) we allow for a continuous range of policy options rather than simply three or four discrete policy paths when deriving our max-min, min-max-regret and ambiguity-aversion optimal policy paths; and (iv) and we solve the problem in decentralised market equilibrium by maximising the decision-theoretic criterion subject to all the constraints of the market economy which allows us to use different discount rates and thus different welfare criteria for households and the policymaker.

The outline of this paper is as follows. Section 2 reviews Pascal's problem analytically and section 3 shows how it can be adapted to the problem of dealing with climate deniers. Section 4 gives numerical illustrations of how to calculate various socially optimal outcomes based on expected-utility, max-min and min-max-regret analysis using a calibrated integrated assessment model of the global economy. Section 5 shows how these approach can be nested using ambiguityaversion analysis. Section 6 presents outcomes under various changes in assumptions to give a more realistic assessment and show the robustness of our claim that carbon should be priced even if taking account of the presence of climate deniers. Section 7 concludes. 


\section{Pascal's problem}

Let us first consider Pascal's problem with the following table of costs of actions. Normalising so that the cost of not believing when God does not exist is zero, the cost of not believing in God when God does exist is eternal damnation with $b \rightarrow \infty$. Believing in God when God does exist leads to bliss in Paradise and thus $a \rightarrow \infty$. The cost of believing in God when God does not exist is the cost of conforming (e.g., not swimming on Sunday) so $c>0$ is small and finite. Denote the probability that God does not exist by the constant $0<\pi<1$.

Table 1: Decision matrix for Pascal's problem

\begin{tabular}{|c|cc|}
\hline Pay-off & $\begin{array}{c}\text { Belief } \\
\text { in God }\end{array}$ & $\begin{array}{c}\text { Do not believe } \\
\text { in God }\end{array}$ \\
\hline God exists & $a$ & $-b$ \\
God does not exist & $-c$ & 0 \\
\hline min pay-off & $-c$ & $-b$ \\
max pay-off & $a$ & 0 \\
\hline
\end{tabular}

Key: The max-min and max-max policies lead one to believe in God with pay-offs $-c>-b$ and $a>0$, respectively, irrespective of how close the probability that God does not exist, $\pi$, is to 1 . The same outcome holds for expected-utility analysis.

The expected pay-off to believers, $(1-\pi) a-\pi c$, thus exceeds the pay-off to non-believers, $-(1-\pi) b$, if and only if the probability that God exists exceeds $0<c /(a+b+c)<1$. Since $a \rightarrow \infty$ and $b \rightarrow \infty$ (strictly speaking, only one of these conditions is needed), the cut-off probability is infinitesimally close to zero. So unless one is an atheist and leaves no room for doubt at all, expected utility analysis drives a rational person to believe in God. Since clearly $c<b$, the penultimate row of Table 1 indicates that believing is also the pessimistic max-min policy. The bottom row of Table 1 indicates it is also the more optimistic max-max policy. If one believes in God and God does not exist, the regret is $a+c$. If one does not believe in God but God does exist, the regret is $b$. The min-max-regret policy is thus to believe in God provided that $a+c<b$. Hence, although expected-utility, max-min and max-max analysis leads one to decide to believe in God, the min-max-regret policy only leads one to believe in God if the cost of Hell and Eternal Damnation dominates the benefit of Paradise plus the small cost of wrongly believing in God. 


\section{Decision theory: climate policy under fundamental model uncertainty}

We will apply a similar line of reasoning to analyse climate model uncertainty as in section 2 when discussing Pascal's problem. Before we do this, it may be helpful to relate our analysis to Hume's induction problem. ${ }^{7}$ This problem was stated by Hume in A Treatise of Human Nature (1739, Book 1, part iii, section 6) and An Enquiry Concerning Human Understanding (1748, section iv) and deals with the problem of how to explain why we form any conclusions that go beyond the past instances of which we had experience. Hume's concern is with inductive inferences such as (a) all instances of bread (of a particular appearance) have been nourishing; (b) the next instance of bread (of that appearance) will be nourishing. A similar problem arises with our treatment of climate deniers. Although the laws of physics underlying the phenomenon of global warming have been consistent in the past, this may not be the case in the future. This may explain why some people, including a small proportion of scientists, ascribe to the view that global warming does not exist despite past evidence and the fundamental laws of physics. Our findings in both here and the numerical sections 4-6 that follow will then have to be interpreted as that the prior probability that the climate denier view is correct has to be very (unrealistically) large to have a noticeable impact on the optimal response to climate change and the associated path of carbon prices. Importantly, the prior probability that climate deniers are correct does not stem from science. Our policy advice is rational but thus takes account of possibly irrational prior probabilities of climate deniers being right. The reason underlying this apparent contradiction is that agnostic policy makers give credence to both climate scientists and climate deniers in order to come to policies that may be acceptable to all parties and that are robust to either view being a possible outcome.

Table 2 takes an approach similar to Pascal's problem discussed in section 2 to the problem of formulating climate policy when climate deniers are taken seriously. The first row corresponds to the view that anthropogenic warming exists, which is the view of (the vast majority of) climate scientists. The second row corresponds to the view that anthropogenic warming does not exist, which is the view of climate deniers. The actions for each of the two columns correspond to pricing carbon to internalise the damages from global warming (and rebating the revenue to the private sector) and to business as usual, respectively. Not taking action to fight climate change when the climate scientists are right leads to a rise in mean global temperatures in excess of 4 degrees Celsius

\footnotetext{
${ }^{7}$ We are very grateful to one of the referees for suggesting to relate our treatment of climate deniers to Hume's induction problem.
} 
with large drops in economic activity, but taking action would have mitigated heating and welfare losses. Taking account of this public good problem, the view of climate scientists is that $0<a<b$.

Table 2: Decision matrix for climate policy when deniers are taken seriously

\begin{tabular}{|c|cc|}
\hline Pay-off & Price carbon & $\begin{array}{c}\text { Do not price } \\
\text { carbon }\end{array}$ \\
\hline Climate science & $-a$ & $-b$ \\
Climate deniers & $-c$ & 0 \\
\hline min pay-off & $-a$ & $-b$ \\
max pay-off & $-c$ & $\mathbf{0}$ \\
\hline
\end{tabular}

Taking climate action when climate deniers are right implies that there are some welfare costs of unnecessarily distorting energy decisions, so the view of climate deniers corresponds to $0<c$. We furthermore suppose that $c<a$, so that pricing carbon leads to higher welfare if climate deniers are right than if climate scientists are right (since pricing carbon would not mitigate all emissions from now onward and human emissions do not damage welfare if climate deniers are right). Using expected-utility analysis as before, it follows that global policy makers should take climate action if and only if the probability that climate scientists are correct exceeds $c /(b-a+c)$ or equivalent if the probability that climate deniers are correct is less than $(b-a) /(b-a+c)$. Since $b>a$ and $c>0$, both these probabilities are between zero and one.

Assumption 1: The regret of not taking climate action if climate scientists are right, $b-a>0$, exceeds the regret of taking climate action if climate deniers are right, $c>0$. Pricing carbon leads to a bigger welfare loss if climate scientists are right than if climate deniers are right, $a>c$.

This assumption is plausible and we will see that it holds for our numerical work in sections 4-6 below. Not conducting any climate policies if temperature rises substantially to say 4-7 degrees Celsius induces relatively big losses in economic output and welfare, whereas pricing carbon and rebating the revenue when anthropogenic global warming occurs leads to relatively small welfare loss triangles. It follows from the first part of Assumption 1 that a sufficient condition for climate action to take place is that the probability of climate deniers being right is less than $50 \%$ (as $(b-a) /(b-a+c)$ is bigger than $50 \%)$. Since $97 \%$ of scientists and $58 \%$ of the general public in the USA say that human activity is a significant contributing factor in changing mean global temperature, one can safely assume this threshold for pricing carbon is met (Doran and 
Zimmerman, 2009). Furthermore, the max-min-regret policy is always to price carbon and to take action to fight global warming. The second part of Assumption 1 states that if carbon is priced the welfare loss is higher without than with anthropogenic global warming, $a>c$. It follows that the max-min policy is to price carbon. Since similar results hold for expected-utility, min-max-regret and max-min analysis, the robust policy is to undertake to fight global warming by pricing carbon emissions either via a global carbon tax or via a competitive market for emission rights. This could be contrasted with the max-max policy (doing the best under the best possible outcome), which leads global policy makers always to not price carbon.

We summarise the above in the following result.

Result 1: If Assumption 1 holds and there is a choice of only two actions, namely to price or not to price carbon, the max-min and min-max-regret policies are to price carbon. Under expected utility analysis, a sufficient condition for policy makers to price carbon is that the probability of climate deniers holding the correct view is less than 50\%. The max-max policy is to do nothing.

Modern decision theory also allows for ambiguity aversion (Klibanoff et al., 2005). Effectively, policy makers thus have an aversion to not knowing what the right climate model is. This approach accounts for irreducible model uncertainty and puts a premium on playing it safe when venturing into domains where different models give different outcomes (Millner et al, 2013). As in the following sections 4-6, we assume that policy $p$ can take on a continuum of values instead of only two values ('to price or not to price carbon'). It is perhaps easiest to think of $p$ as the initial carbon price which henceforth grows at the same rate as world GDP (cf. Golosov et al., 2014; van den Bijgaart et al., 2016; Rezai and van der Ploeg, 2016). Formally, if $A A>0$ denotes the coefficient of relative ambiguity aversion, $W_{S}(p)$ denotes the welfare criterion if climate scientists are right and $W_{D}(p)$ denotes the welfare criterion if the climate deniers are right, the agnostic policy maker with ambiguity aversion chooses policies $p$ to maximise the expected value $\left((1-\pi) W_{S}(p)^{1-A A}+\pi W_{D}(p)^{1-A A}-1\right) /(1-A A)$ if $A A \neq 1$ and $(1-\pi) \ln \left(W_{S}(p)\right)+\pi \ln \left(W_{D}(p)\right)$ if $A A=1$.

This formulation nests both the expected welfare approach (with $A A=0$ ) and the extremely cautious max-min approach (with $A A=\infty$ ). The first-order optimality condition is $(1-\pi) W_{S}{ }^{\prime}(p) W_{S}(p)^{-A A}+\pi W_{D}{ }^{\prime}(p) W_{D}(p)^{-A A}=0$ which can be rewritten as (Millner et al., 2013): 


$$
\left(1-\pi^{*}\right) W_{S}{ }^{\prime}(p)+\pi^{*} W_{D}{ }^{\prime}(p)=0, \text { where } 0 \leq \pi^{*} \equiv \pi /\left(\pi+(1-\pi)\left(W_{D}(p) / W_{S}(p)\right)^{A A}\right) \leq 1 \text {. }
$$

Allowing for ambiguity aversion is thus equivalent to maximising expected welfare provided one replaces the probability $\pi$ by the ambiguity-aversion-adjusted probability $\pi^{*}$. Note that $W_{D}(p)>W_{S}(p)$ under Assumption 1, so that deniers of (anthropogenic) global warming have a higher perceived welfare. Assuming that welfare levels $W_{D}(p)$ and $W_{S}(p)$ are both positive (or both negative), we see that $\pi^{*}$ increases in $\pi$. Furthermore, ambiguity aversion $(A A>0)$ implies that $\pi^{*}<\pi$ and that $\pi^{*}$ decreases in $A A$. We also note that with $W_{S}{ }^{\prime}(p)>0$ for $p$ smaller than the optimal $p$ if climate scientists are right as would be the case when taking account of the view of climate deniers (and $W_{S}{ }^{\prime}(p)=0$ for optimal $p$ if climate scientists are right) and $W_{D}{ }^{\prime}(p)<0$ for any positive $p$ as climate deniers see any carbon tax as distorting and welfare deteriorating. We thus find that, provided $A A>0, \pi^{*}$ increases in $p$ for the relevant range for the price of carbon $p$. We thus establish that $\pi^{*}=\pi^{*}(\pi, A A, p)$ with $\pi_{\pi}^{*}>0, \pi_{A A}^{*}<0$ and $\pi_{p}^{*}>0 .{ }^{8}$ If the carbon price is below that what would hold in the view of the climate scientists, we establish the following result.

Result 2: Assume $W_{S}^{\prime \prime}(p)<0$ and $W_{D}^{\prime \prime}(p)<0$. Accounting for relative ambiguity aversion in policy making, $A A>0$, introduces caution and requires downward adjustment of the probability that climate deniers are right and upward adjustment of the optimal carbon price, p. Climate action is also more ambitious if the subjective probability that climate deniers are right, $\pi$, is low.

Proof: The left-hand side of (1) decreases in $p$ because the second-order condition for a maximum must be satisfied. Assumptions $W_{S}^{\prime \prime}(p)<0$ and $W_{D}^{\prime \prime}(p)<0$ ensure that this is the case. Since the lefthand side of (1) also decreases in $\pi^{*}$ as $W_{S}{ }^{\prime}(p)>0$ and $W_{D}{ }^{\prime}(p)<0$, we establish that $p=p\left(\pi^{*}\right)$ with $p_{\pi^{*}}<0$. Hence, the optimal price of carbon $p$ decreases in the ambiguity-aversion-adjusted probability that climate deniers are right, $\pi^{*}$. Using the implicit function theorem to solve for the

${ }^{8}$ We have $\frac{d \pi^{*}}{d A A}=-\pi^{*} \frac{1-\pi}{\pi} A A\left(\frac{W_{D}}{W_{S}}\right)^{A A-1}<0$ and $\frac{d \pi^{*}}{d p}=\frac{d \pi^{*}}{d A A} \frac{W_{D} W_{S}^{\prime}-W_{D}^{\prime} W_{S}}{W_{S}^{2}}>0$ which are negative and positive, respectively, for values of $p$ equal or lower than the $p$ which is optimal when there is no doubt that climate scientists are right. Clearly, the optimality condition (1) indicates $\pi^{*}$ that increases in $\pi$. 
optimal carbon price from $p=p\left(\pi^{*}\right)$ and $\pi^{*}=\pi^{*}(\pi, A A, p)$, we get $\pi^{*}=\pi^{*}(\pi, A A)$ with $\pi_{\pi}^{*}>0$ and $\pi_{A A}^{*}<0$ and $p=p(\pi, A A)$ with $p_{\pi}<0$ and $p_{A A}>0$.

So far, armchair arguments have led to Results 1 and 2. To get a more realistic analysis, we adapt a commonly used integrated assessment model of climate change and the economy to allow for a variety of climate models and damage models. This allows us to put some numbers to Results 1 and 2 by obtaining options for robust climate policy where the policy actions $p$ are now just a continuous stream of time-varying carbon prices starting from the present.

\section{Pricing carbon under conflicting views of global warming}

To implement the two opposing views of the climate-economy interaction - one in which human emissions contribute to climate change and one in which the climate follows exogenous projections of committed warming - we adapt and extend the most commonly used integrated assessment model DICE as presented in Nordhaus (2014) and describe our adaptation and chosen parameter values in the Appendix. The "scientific" view corresponds to the DICE-2013R version of the DICE. Strictly speaking, the International Panel on Climate Change allows for a very small probability that deniers are right but we will call the "science" view the one which says that anthropogenic carbon emissions contribute to global warming. The "denier" model corresponds to a variant of DICE-2013R where (future) anthropogenic emissions do not enter the atmosphere and the climate evolves independently of the economy, responding to exogenous and past emissions already in the system. Hence, peak mean temperature fixed at $1.3^{\circ} \mathrm{C}$.

To start off, we assume that the two rival views only differ in their view of the causes of global warming. Both views use in our exercise the same model of economic growth, consumption and energy use and also the same damages from global warming, namely the ones of DICE. Although climate deniers might differ in their degree of impatience and their willingness to make sacrifices

for future generations, we assume first that climate deniers and climate scientists employ the same social rate of impatience and relative intergenerational inequality aversion and thus the same social discount rate as climate scientists. Given these benchmark assumptions, we let agnostic policy makers choose climate policy under this form of "climate model" uncertainty. For simplicity we ignore "statistical" uncertainties in any particular model. 
Figure 1 plots the temperature profiles for both views of the climate. ${ }^{9}$ The dashed green line with temperature peaking at $3.4^{\circ} \mathrm{C}$ corresponds to the science view where decision makers price carbon at $\$ 21.1 / \mathrm{tCO} 2$ in 2020 to avoid excessive climate change. Under the deniers' view global temperature is unrelated to human emissions and peaks at $1.3^{\circ} \mathrm{C}$ regardless of policy as can be seen from the dashed-dotted blue line. To avoid unnecessary regulation, it is optimal to avoid any carbon price if policy makers hold the view that anthropogenic global warming does not exist. ${ }^{10}$

We also consider scenarios where one type of policy (price carbon or don't price carbon) is implemented in the other type of climate view (science or denier). In the science/don't price carbon case, the absence of a carbon price leads to rapidly rising temperature, peaking at $7^{\circ} \mathrm{C}-$ see the dotted line. This is commonly called "business as usual" or BAU. In the denier/price carbon case (not plotted), human carbon emissions fall but temperature is unchanged due to the decoupling of temperature and emissions.

Table 3 summarises the four scenarios in terms of global welfare gains, which we define in percentage of current world GDP relative to BAU, ${ }^{11}$ and is our benchmark numerical analogue of Table 2. The first row assumes that the science view is correct. Wrongly not pricing carbon when climate scientists are right as in business as usual involves unfettered growth in emissions, temperature peaking at $7^{\circ} \mathrm{C}$ and consequently severe damages to the world economy. However, if carbon is priced, temperature is stabilised and welfare is increased by $17 \%$ of current world GDP relative to business as usual. The second row assumes that climate deniers are right. Temperature increases to $1.3^{\circ} \mathrm{C}$ regardless of policy and the economic future under business as usual is much brighter than what doomsayer scientists think. The benefit of removing severe climate change damage amounts to $41 \%$ of world GDP. In a climate denier's world, wrongly and unnecessarily pricing carbon and rebating the revenues introduces efficiency losses and a drag on economic growth equivalent to a drop in $7 \%$ of world GDP.

\footnotetext{
${ }^{9}$ Mitigation is limited in DICE to $100 \%$ of emissions for 150 years and to $120 \%$ from then onwards. These upper bounds for the carbon price are the reason for the non-monotonic price curve in Figure 1. As soon as mitigation reaches its upper bound, the carbon price follows the exogenous (falling) cost of the backstop. The social cost of carbon and the marginal cost of abatement diverge from then on and the carbon price is capped at the latter due to technological constraints.

${ }^{10}$ Despite a zero carbon price, emission abatement under the climate deniers' view is positive and driven by the endogenous Hotelling rent as total availability of fossil fuels is limited in DICE.

${ }^{11}$ This corresponds to the equivalent increase in current consumption as a share of GDP to have the same welfare over the entire time horizon as under BAU. Mechanically, we take the difference in aggregate utility from BAU and divide by marginal utility (to convert into consumption units) and initial world GDP (to convert into \% of GDP).
} 
Figure 1: Temperature, carbon prices, and emissions (abated and cumulated)

in the science and denier's models under either policy.
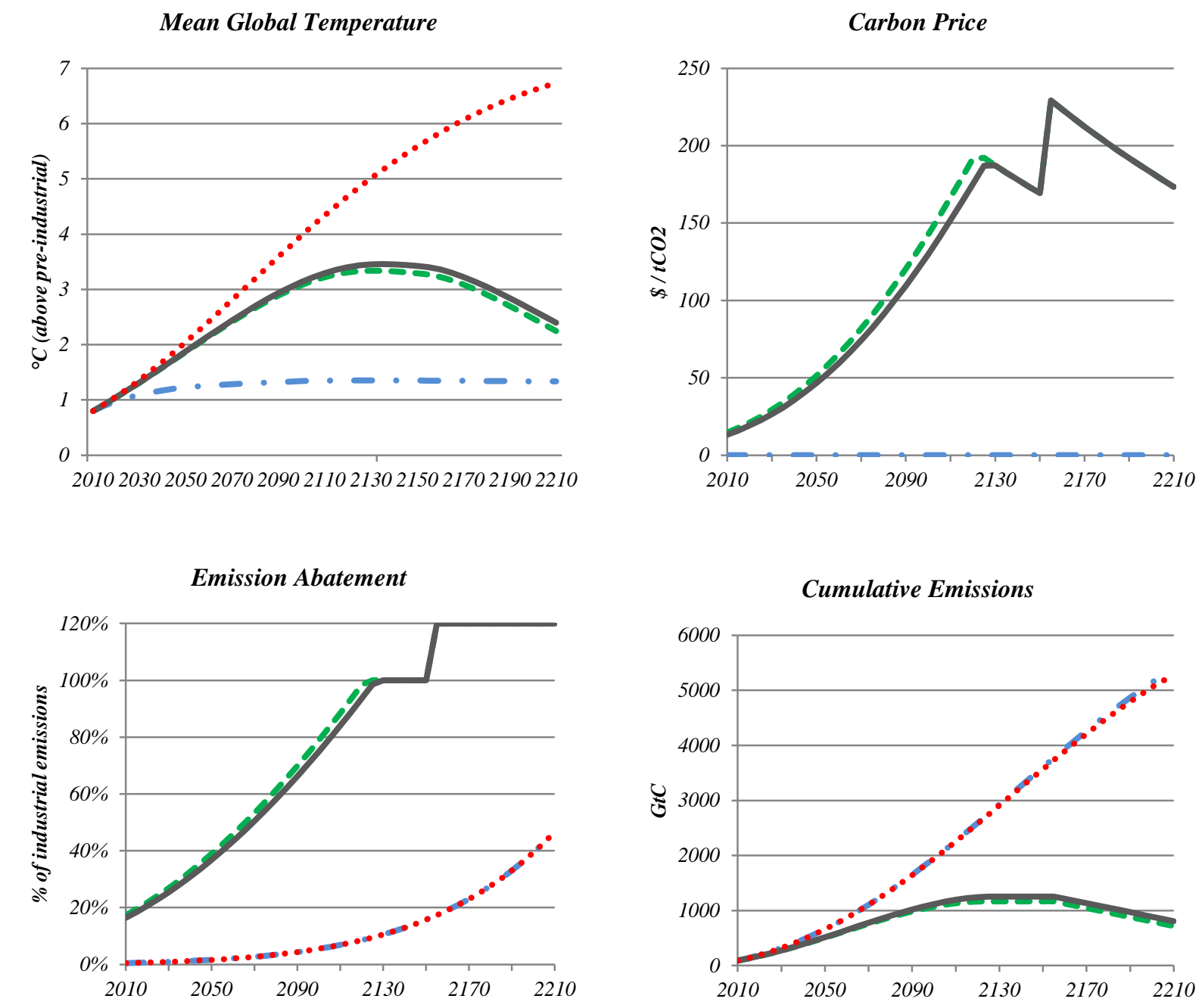

- Science - - Denier ..... Science w. Denier policy (BAU)

Expected Utility w. $10 \%$ prob Denier

Key: Optimal climate policy (dashed green) limits peak global warming (PW) to $3.4^{\circ} \mathrm{C}$ in the science (DICE) model. Climate deniers (dot-dashed blue) hold the view that temperature is independent of policy and thus fossil fuel is phased out only due to its limited availability. This policy of no carbon prices and relative in-action translates into $7^{\circ} \mathrm{C} \mathrm{PW}$ if the science view on anthropogenic global warming is right (dotted red line). Expected-utility analysis giving a $10 \%$ probability that climate deniers are right (solid black) leads to a carbon price almost identical to the science case. 


\section{Table 3: Welfare gains under climate model uncertainty (\% initial world GDP, relative to BAU under the science view)}

\begin{tabular}{|c|cc|}
\hline Climate view & Price carbon & $\begin{array}{c}\text { Don't price } \\
\text { carbon }\end{array}$ \\
\hline Science & $17 \%$ & $0 \%$ \\
Denier & $34 \%$ & $41 \%$ \\
\hline min welfare & $\mathbf{1 7 \%}$ & $0 \%$ \\
max regret & $\mathbf{7 \%}$ & $17 \%$ \\
\hline
\end{tabular}

Key: Pricing carbon increase welfare by $17 \%$ if scientists are correct but lowers welfare by $7 \%$ if deniers are right. The welfare under carbon pricing is lower if climate scientists are right (17\%) than if climate deniers are right (34\%).

If one follows Pascal and adopts the expected-welfare approach with only these two policies, it is optimal to price carbon if and only if the probability that climate deniers are right is less than $70 \%$ and not to price carbon otherwise. ${ }^{12}$ Agnostic policy makers who maximise welfare under the worst possible outcomes (the max-min decision criterion), also choose to price carbon, because the resulting efficiency losses are much lower than the deleterious effects of future severe climate change (in a $7^{\circ} \mathrm{C}$ world). The same logic and climate policy applies if policy makers minimise maximum regret, since the regret of not pricing carbon when climate scientists turn out to be right (17\% of world GDP) exceeds the regret of pricing carbon when climate deniers turn out to be right (7\% of world GDP). Both max-min and min-max-regret policies are the classical policy responses to model uncertainty. They maximise welfare or minimise regret under the worst possible view of global warming and compel policy maker to price carbon even when taking climate deniers seriously.

So far we have only considered either-or choice (for one either believes in God or doesn't), but the modern expected-welfare approach allows for a continuous range of policy options. We find that maximising expected welfare with a $10 \%$ probability that climate deniers hold the correct view of the world (solid black lines in Figure 1) does not alter the purely science-based optimal climate policy much: the price of carbon falls from $\$ 21.1$ to $\$ 19.1 / \mathrm{tCO} 2$ and expected peak warming rises by a mere $0.1^{\circ} \mathrm{C}$. Expected-utility outcomes for further levels of $\pi$ are reported in Table 4 .

\footnotetext{
${ }^{12}$ As discussed in section 3, the key difference is that Pascal's argument requires either infinite welfare in Paradise or infinite negative welfare if in hell whereas in the climate context these welfare effects are finite. If $\pi$ is the subjective probability that deniers are correct, expected welfare when carbon is priced yields higher expected welfare than not pricing carbon if $0.17(1-\pi)+0.34 \pi>0.41 \pi$ or $\pi<70 \%$.
} 
Table 4: Peak warming and carbon prices under different priors that deniers are correct

Prior that deniers hold correct view

\begin{tabular}{cccccccccccc} 
& $0 \%$ & $10 \%$ & $20 \%$ & $30 \%$ & $40 \%$ & $50 \%$ & $60 \%$ & $70 \%$ & $80 \%$ & $90 \%$ & $100 \%$ \\
\hline Peak Warming & $3.3^{\circ} \mathrm{C}$ & $3.5^{\circ} \mathrm{C}$ & $3.6^{\circ} \mathrm{C}$ & $3.8^{\circ} \mathrm{C}$ & $3.9^{\circ} \mathrm{C}$ & $4.2{ }^{\circ} \mathrm{C}$ & $4.5^{\circ} \mathrm{C}$ & $4.8^{\circ} \mathrm{C}$ & $5.4{ }^{\circ} \mathrm{C}$ & $6.3^{\circ} \mathrm{C}$ & $7.0^{\circ} \mathrm{C}$ \\
\hline $\begin{array}{c}\text { Carbon Price } \\
(2020, \text { per tCO2) }\end{array}$ & $\$ 21.1$ & $\$ 19.1$ & $\$ 17.1$ & $\$ 15.0$ & $\$ 12.9$ & $\$ 10.8$ & $\$ 8.7$ & $\$ 6.6$ & $\$ 4.4$ & $\$ 2.2$ & $\$ 0.0$ \\
\hline
\end{tabular}

Key: Peak warming levels increase from $3.3^{\circ} \mathrm{C}$ to $7^{\circ} \mathrm{C}$ and carbon prices (in 2020) decrease from $\$ 21.1$ to $\$ 0$ per tCO2 as the prior that deniers are correct, $\pi$, rises from $0 \%$ to $100 \%$.

Peak warming rises non-linearly from $3.3^{\circ} \mathrm{C}$ to $7.0^{\circ} \mathrm{C}$ as the probability that science has it wrong rises from $0 \%$ to $100 \%$. Not surprisingly, the optimal carbon price under expected-utility analysis falls linearly in the probability from the optimal carbon price ignoring climate uncertainty, $\$ 21.1 / \mathrm{tCO} 2$, to the price under business as usual, $\$ 0 / \mathrm{tCO} 2$.

If we take $\pi$ to be $3 \%$ for the climate specialists and $42 \%$ for the general public, as suggested in Doran and Zimmerman (2009), the carbon taxes are \$20.5 and \$12.5 per ton of emitted CO2 and peak warming levels are $3.4^{\circ} \mathrm{C}$ and $4^{\circ} \mathrm{C}$, respectively.

Our finding that the optimal price of carbon is not much lower than $\$ 21$ per ton of emitted CO2 if due account is taken of climate deniers follows directly from the DICE assumptions of moderate damages and a relatively high discount rate. We think that the price of carbon should be much higher due to more convex and higher damages from global warming and due to policy makers having to employ lower ethical discount rates. As we will see in section 6, this will not alter our qualitative conclusion that giving climate deniers some credence will not depress the optimal price of carbon very much.

\section{Ambiguity aversion: nesting expected-utility and max-min analysis}

How would ambiguity aversion impact agnostic climate policy? From Result 2 we know that in the case of climate change ambiguity aversion induces caution and increases the carbon price for any given $\pi$. Figure 2 shows iso-carbon-price and iso-peak-warming curves for combinations of the subjective prior probability that climate deniers are right, $\pi$ (vertical axis) and the coefficient of relative ambiguity aversion, $A A$ (horizontal axis). In the left panel the carbon price in 2020 
decreases from $\$ 21.1$ to $\$ 0 / \mathrm{tCO} 2$ and in the right panel peak warming increases from $3.4^{\circ} \mathrm{C}$ to $7^{\circ} \mathrm{C}$ as the probability that climate deniers are right increases from zero to one (vertical axis).

The degree of ambiguity aversion $(A A)$ rises from 0 to 800 on the horizontal axis. With $A A=0$, the findings correspond to the expected-utility case discussed above. As $A A$ increases, climate policy becomes more ambitious: carbon price and peak warming levels fall. This can be seen in Figure 2 as iso-price and iso-peak-warming curves are upward sloping.

Holding fixed the probability that deniers are right, $\pi$, increases in ambiguity aversion $A A$ lead to regions with higher carbon prices and lower peak warming levels. For example, the optimal carbon price is $\$ 15 / \mathrm{tCO} 2$ if there is no ambiguity aversion $(A A=0)$ and the probability that climate deniers are right is as high as $\pi=30 \%$. Following the $\$ 15 / \mathrm{tCO} 2$ iso-price curve to $A A=800$ yields a probability of two thirds $(\pi=66 \%)$. A significantly higher probability of climate change being a hoax is needed (i.e., two third instead of one third) to support the same $\$ 15$ price on $\mathrm{CO} 2$ if decision makers are strongly averse to ambiguity.

Similarly, if $A A=0$, peak warming increases by more than $0.5^{\circ} \mathrm{C}$ only for priors that deniers are right greater than a third. If $A A=800$, this cut-off for the prior rises to $70 \%$. Aversion to ambiguity, about what the right climate model is, thus biases priors toward the non-sceptic scientist and encourages more ambitious climate policy. This effect is small for low $A A$, but large for high $A A$. Even if policy makers assign a 50\% (90\%) chance to climate deniers being right, allowing for a high degree of robustness (more than for expected-utility but less than for max-min policy) biases this chance down to $20 \%$ if $A A=800$ (2000). This implies a price of carbon of $\$ 17.1 / \mathrm{tCO} 2$ in 2020 and peak global warming of $3.6^{\circ} \mathrm{C}$. Also, a higher probability of climate deniers being right requires higher ambiguity aversion to keep the carbon price in 2020 constant.

As $A A$ approaches infinity, peak warming falls to $3.4^{\circ} \mathrm{C}$ regardless of prior probabilities about whether climate scientists or deniers are right and converges to the max-min policy. Aversion to ambiguity about scientific uncertainty lowers willingness to tolerate increases in global warming. Policy makers that cannot specify probabilities about whether climate scientists or deniers are right should probably aim for the max-min policy (cf. Gilboa and Schmeidler, 1989). 
Figure 2: Priors, ambiguity aversion and peak warming

(a) Carbon price in $2020(\$ / t C O 2)$

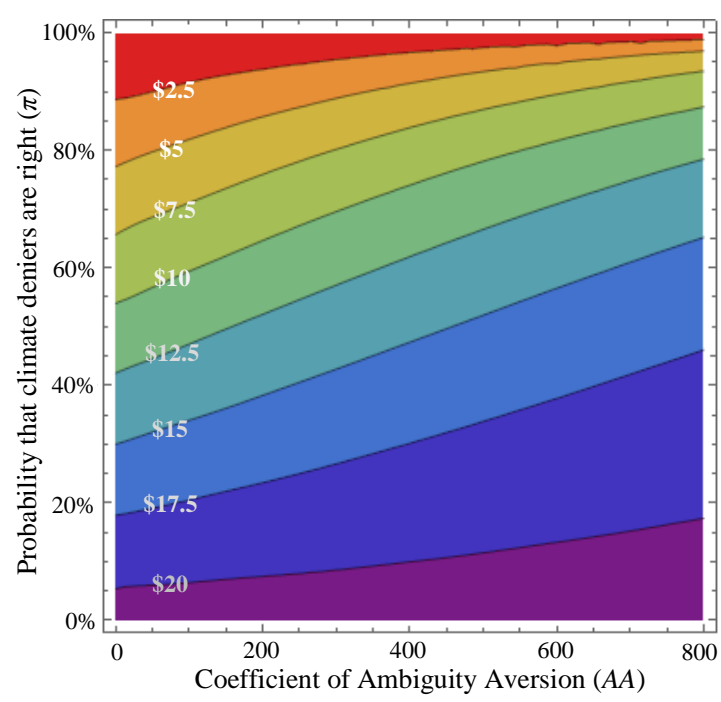

(b) Peak global warming $\left({ }^{\circ} \mathrm{C}\right)$
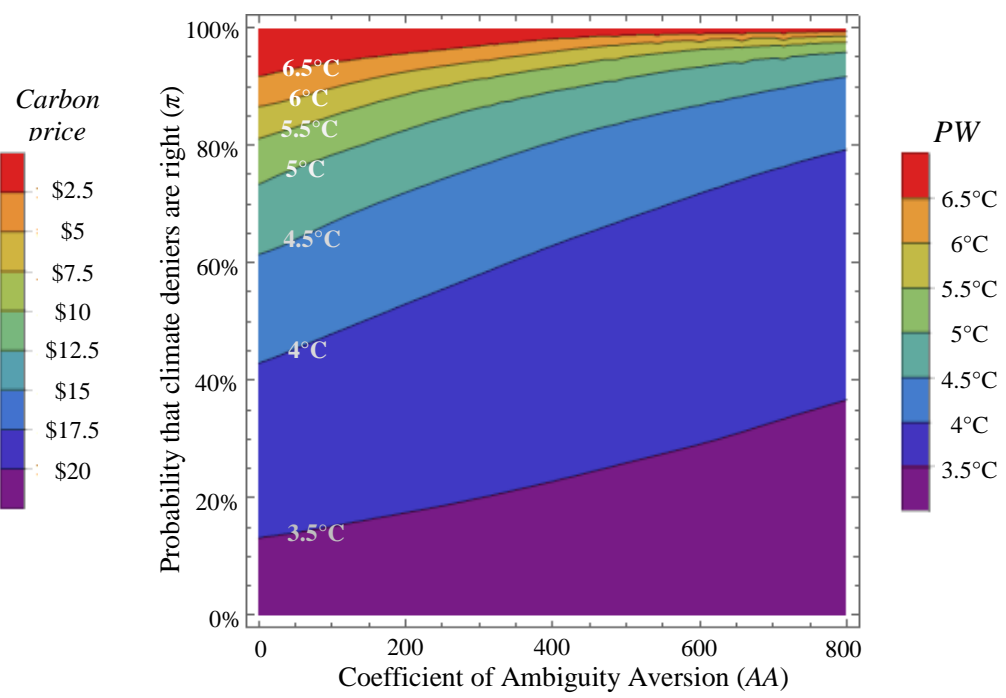

Key: (a) the carbon price in 2020 and (b) peak warming as a function of ambiguity aversion (horizontal axis) and the probability that climate deniers are right (vertical axis). Values for $A A=0$ correspond to those of Table 2. As $A A$ increases, policymakers are more cautious and climate policy is more ambitious: carbon prices increase and peak warming levels fall.

\section{Towards a more realistic assessment: robustness}

The results of sections 4 and 5 build on the published version of DICE-2013R. Here, we explore the robustness of our results by varying (first separately and then jointly) three important determinants of the climate policy: damages, income growth and discount rates. Figure 3 presents these scenarios for the 'science' view and Table 5 summarises the effects on peak warming and the carbon price for different prior probabilities that climate deniers are correct.

\subsection{More convex damages from global warming}

DICE-2013R uses the damage specification of Nordhaus (2008) which aggregates micro estimates of the costs of global warming to macroeconomic costs of $1.7 \%$ of world GDP when global warming reaches $2.5^{\circ} \mathrm{C}$. Weitzman (2010) and Dietz and Stern (2015) argue that damages rise more rapidly at higher levels of global mean temperature than suggested by Nordhaus (2008), but empirical studies on the costs of global warming at higher temperatures are not available. 
Following this reasoning, Ackerman and Stanton (2012) recalibrate damages to fit the additional points of $50 \%$ damage at $6^{\circ} \mathrm{C}$ and $99 \%$ damage at $12.5^{\circ} \mathrm{C} .{ }^{13}$

Figure 3: Robustness of climate policy (the 'science' view) to more convex damages, lower growth rates, and differential discount rates
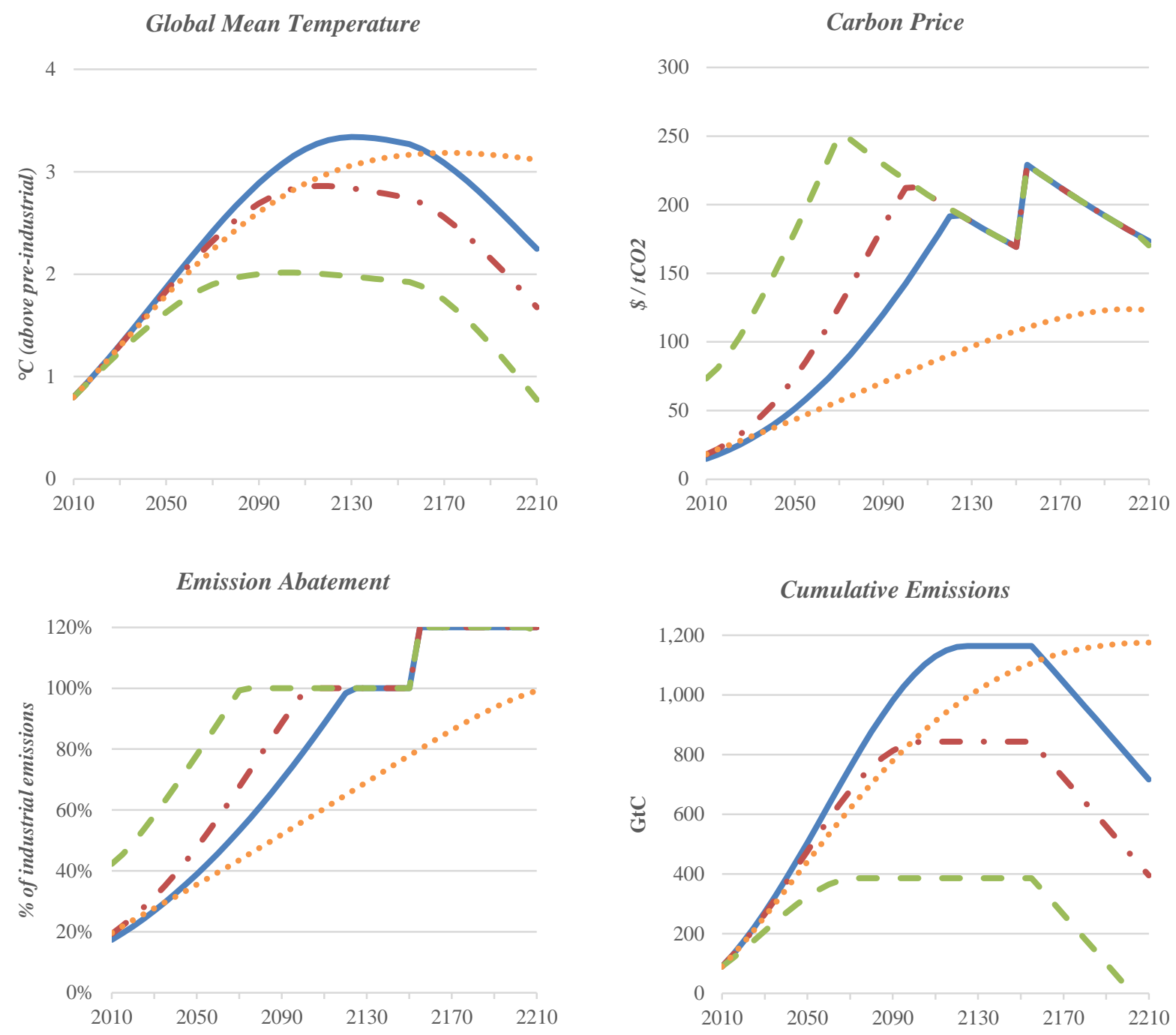

DICE - - More convex damages - - Differential Discounting ..... Lower Growth Rate

13 The damage function (defined as $\%$ of potential output loss in temperature increase $T_{t}$ ) is $1-Z\left(T_{t}\right)=1-\left(1+\zeta_{1} T_{t}^{\zeta_{2}}+\zeta_{3} T_{t}^{\zeta_{4}}\right)^{-1}$ in DICE-07 with $\zeta_{1}=0.00284, \zeta_{2}=2$, and $\zeta_{3}=\zeta_{4}=0$. The recalibration by Ackerman and Stanton (2012) changes these parameter to $\zeta_{1}=0.00245, \zeta_{2}=2, \zeta_{3}=5.021 \times 10^{-6}$, and $\zeta_{4}=6.76$. For temperature increases below $2.5^{\circ} \mathrm{C}$ this recalibration yields lower damages of at most $0.1 \%$ of GDP. DICE2013R uses the damage function $1-\Omega\left(T_{t}\right)=1-0.00267 T_{t}^{2}$ which fits the specification of DICE-07 closely: for $T_{t}<5^{\circ} \mathrm{C}$ the difference is less than $0.1 \%$ of GDP. 
Table 5: Robustness of climate policy to more convex damages, lower growth rates and differential discount rates

\begin{tabular}{clrrrr} 
& & \multicolumn{3}{c}{ Prior that Deniers are Right } \\
& & $0 \%$ & $10 \%$ & $50 \%$ & $100 \%$ \\
\hline \multirow{2}{*}{ DICE-2013R } & Peak Warming & $3.3^{\circ} \mathrm{C}$ & $3.5^{\circ} \mathrm{C}$ & $4.2^{\circ} \mathrm{C}$ & $7.0^{\circ} \mathrm{C}$ \\
& Carbon Price & $21.1 \$ / \mathrm{CO} 2$ & $19.1 \$ / \mathrm{tCO} 2$ & $10.8 \$ / \mathrm{tCO} 2$ & $0.0 \$ / \mathrm{tCO} 2$ \\
\hline More Convex & Peak Warming & $2.9^{\circ} \mathrm{C}$ & $2.9^{\circ} \mathrm{C}$ & $3.3^{\circ} \mathrm{C}$ & $6.6^{\circ} \mathrm{C}$ \\
Damages & Carbon Price & $26.7 \$ / \mathrm{CO} 2$ & $24.7 \$ / \mathrm{tCO} 2$ & $16.2 \$ / \mathrm{tCO} 2$ & $0.0 \$ / \mathrm{tCO} 2$ \\
\hline \multirow{2}{*}{ Lower Growth } & Peak Warming & $3.2^{\circ} \mathrm{C}$ & $3.3^{\circ} \mathrm{C}$ & $3.9^{\circ} \mathrm{C}$ & $5.3^{\circ} \mathrm{C}$ \\
& Carbon Price & $24.7 \$ / \mathrm{CO} 2$ & $22.3 \$ / \mathrm{tCO} 2$ & $12.6 \$ / \mathrm{tCO} 2$ & $0.0 \$ / \mathrm{tCO} 2$ \\
\hline Differential & Peak Warming & $2.0^{\circ} \mathrm{C}$ & $2.1^{\circ} \mathrm{C}$ & $2.6^{\circ} \mathrm{C}$ & $7.0^{\circ} \mathrm{C}$ \\
Discounting & Carbon Price & $91.3 \$ / \mathrm{tCO} 2$ & $83.7 \$ / \mathrm{tCO} 2$ & $51.1 \$ / \mathrm{tCO} 2$ & $0.0 \$ / \mathrm{tCO} 2$ \\
\hline
\end{tabular}

Having more convex damages increases the marginal cost of climate change which makes climate policy more ambitious. Consequently, peak warming falls to $2.9^{\circ} \mathrm{C}$ and the carbon price in 2020 increases to $26.7 \$ / \mathrm{tCO} 2$ in Figure 3 (dot-dashed red lines) and Table 5.

Table 6 reports the welfare effects of climate action (and inaction) for the science and denier world views. The more convex damage function increases the damages from climate change at high levels of temperature. This increases the cost of not pricing carbon significantly from 17\% to $189 \%$ of initial world GDP (compared to the baseline calibration of section 4). More ambitious climate policy increases the cost of inefficient legislation in the denier's world from 7\% to $12 \%$ of GDP. The regret of not taking climate action when the scientists turn out to be right is boosted from 17\% to $189 \%$ of world GDP whilst the regret of taking climate action when the deniers turn out to be right increases from $7 \%$ to a mere $12 \%$ of world GDP. More convex damages thus increase the case for taking climate action based on max-min or min-max-regret policies. More convex damages also induce the agnostic policy maker to be more cautious and use more aggressive climate policy with positive $\pi$, as reported in Table 5. Allowing for a 50-50 chance that climate change is not man-made increases peak warming by a mere $0.4^{\circ} \mathrm{C}$ to $3.3^{\circ} \mathrm{C}$. 
Table 6: Welfare gains (\% initial world GDP) under convex damages

\begin{tabular}{|c|cc|}
\hline Climate view & Price carbon & $\begin{array}{c}\text { Don't price } \\
\text { carbon }\end{array}$ \\
\hline Science & $189 \%$ & $0 \%$ \\
Denier & $204 \%$ & $216 \%$ \\
\hline min welfare & $\mathbf{1 8 9 \%}$ & $0 \%$ \\
max regret & $\mathbf{1 2 \%}$ & $189 \%$ \\
\hline
\end{tabular}

\subsection{Lower TFP growth}

Relative affluence of future generations is a key determinant of climate policy. The richer future generations are, given the social discount rate, $\rho$, and the degree of intergenerational inequality aversion, IIA, the less justifiable the sacrifice of climate policy imposed on current generations. Here, we cut the trend rate of future total factor productivity growth in half. Lower income growth lowers the interest applied to discount future climate damage and thus increases the initial optimal carbon price to $24.7 \$ / \mathrm{tCO} 2$ (which is slightly higher than in the scenario with more convex damages). However, this higher level of carbon pricing does not translate in significantly lower peak warming levels, because the lower income growth also lowers the growth trajectory of the carbon price as shown in Figure 3.

Table 7: Welfare gains (\% initial world GDP) under lower TFP growth

\begin{tabular}{|c|cc|}
\hline Climate view & Price carbon & $\begin{array}{c}\text { Don't price } \\
\text { carbon }\end{array}$ \\
\hline Science & $11 \%$ & $0 \%$ \\
Denier & $33 \%$ & $38 \%$ \\
\hline min welfare & $\mathbf{1 1 \%}$ & $0 \%$ \\
max regret & $\mathbf{5 \%}$ & $11 \%$ \\
\hline
\end{tabular}

Lower growth in the economy lowers cumulative carbon emissions and the threat of climate change. With peak warming delayed by four decades to 2170 , the present discounted value of inaction falls to $11 \%$ as can be seen from Table 7. Less stringent climate policy, however, also lowers the cost of policy in the denier's view of the world to 5\% of GDP. More importantly, the robust max-min and min-max-regret policies that follow from Table 7 again point towards pricing carbon even when taking account of the view of climate deniers. 


\subsection{Different discount rates for private agents and policy makers}

Much of the debate around the Stern Review centered on the role of social discounting of future welfare. Stern (2007) prominently echoed Ramsey (1928) arguing that it is unethical to discount future welfare and that market rates of interest are not a good guide to social discount rates. Further detailed discussion of this ethical viewpoint can be found in Stern (2015) and Gollier (2018). Nordhaus (2008) leads the opposition to this view by arguing that these ethical parameters are not really ethical but need to be chosen such that simulated interest rates match those observable in the market. Following von Below (2012), Schmitt (2014), Belfiori (2017) and Barrage (2018), we sidestep this debate by allowing differential discounting for private agents and policy makers. The former discount in the spirit of Nordhaus, calibrated to reflect market interest rates, while the latter are free to follow ethical considerations, in our model following Stern's view. To do so, we lower the social discount rate, $\rho$, from $1.5 \%$ to $0.1 \%$ per year and decreasing the degree of intergenerational inequality aversion, IIA, which equals the inverse of the intertemporal elasticity of substitution, from 1.45 to 1 . The saving decisions of private agents thus continue to employ $\rho=1.5 \%$ per year and $I I A=1.45$, the values used in DICE-2013R. ${ }^{14}$ With a trend growth rate of $2 \%$ per year, the interest rate applied to private decisions is by the Keynes-Ramsey rule $1.5+1.45$ x $2=4.4 \%$ per year but the interest rate applied to social decisions is $0.1+1 \times 2=2.1 \%$ per year. So the difference between interest rates employed by the private sector and policy makers is $2.3 \%$ per year and this difference increases as economic growth slows along the growth path.

A lower discount rate increases the weight placed on the welfare future generations and strengthens climate policy. Peak warming falls to $2.0^{\circ} \mathrm{C}$ and the carbon price increases to as much as 91.3\$/tCO2 (see long dashed, green lines in Figure 3 and Table 5). Placing higher welfare weight on the future also increases the cost of inaction under BAU. Table 8 recalculates Table 3 for the case of differential discounting. If policy makers do the best under the worst possible view of the world, they price carbon as $968 \%$ exceeds $0 \%$ of world GDP. If they minimise the maximum regret from conducting the wrong policy, they also price carbon as the regret from pricing carbon if deniers turn out to be right, $160 \%$ of world GDP, is less than the regret from not pricing carbon if

\footnotetext{
${ }^{14}$ We model the private and social decisions as a Stackelberg game with the government as the leader and private agents as followers. We assume that the government can commit to future policies. With differential discount rates, our equilibrium will be time inconsistent and future policy makers would like to deviate.
} 
the scientists turn out to be right, $968 \%$ of world GDP. The case for pricing carbon, and ambitiously, is thus starkly enhanced.

\section{Table 8: Welfare gains (\% initial world GDP) with a low discount rate for policy makers and a higher discount rate for private agents}

\begin{tabular}{|c|cc|}
\hline Climate view & Price carbon & $\begin{array}{c}\text { Don't price } \\
\text { carbon }\end{array}$ \\
\hline Science & $968 \%$ & $0 \%$ \\
Denier & $991 \%$ & $1151 \%$ \\
\hline min welfare & $\mathbf{9 6 8 \%}$ & $0 \%$ \\
max regret & $\mathbf{1 6 0 \%}$ & $968 \%$ \\
\hline
\end{tabular}

As mentioned already, we find that the scenario based on the DICE assumptions leads to an unrealistically low carbon price. More convex damages do not do much in terms of raising the carbon price (see Table 5). However, these would kick in much more under economic, growth and damage uncertainty, especially if the distributions driving these uncertainties are more skewed (e.g., van der Ploeg and van den Bremer, 2018). We therefore choose as our preferred scenario the one with Nordhaus damages and differential discounting rates for policy makers and private agents. Hence, for our purposes the headline message is that the scientific optimal carbon price of $\$ 91 / \mathrm{tCO} 2$ is cut to only $\$ 84 / \mathrm{tCO} 2$ if climate deniers are given a credence probability of $10 \%$. Peak warming would then be only marginally higher, i.e., $2.1^{\circ} \mathrm{C}$ instead of $2.0^{\circ} \mathrm{C}$

\subsection{Multiple types of model uncertainty: damage and growth uncertainty combined}

So far we have only studied the risks stemming from damage and growth uncertainty separately. In reality, integrated assessment models of climate and the economy have been criticised severely (Pindyck, 2017) and it is a big improvement if it is recognised that policy makers need to face a multitude of known (and unknown) unknowns simultaneously (e.g., Heal and Millner, 2014; Rezai and van der Ploeg, 2018b; Brock and Sargent, 2017; Berger and Marinacci, 2017). Following the modular approach to formulating the problem of optimal climate formulation (cf., NAS, 2017; Rezai and van der Ploeg, 2018a), one could think of different damage models for the effect of temperature on aggregate production (additive versus multiplicative, more or less convex, etc.), different climate models for the stock of carbon in the atmosphere and global mean temperature (2-box, 3-box or 4- box models, including lags in temperature response or not, including positive feedback loops or not, etc.), different economic models (endogenous or exogenous growth, the 
global economy versus a multitude of countries, etc.) and different models of ethics and preferences (low or high discount rates, low of high willingness to sacrifice consumption for future generations). In this section we outline for purely illustrative purposes how climate policy robust to uncertain growth rates and damages from climate change could be derived.

Table 9 presents an extended version of the table format presented in previous sections. Each row corresponds to a state of the world in which damages are either high (as in section 6.1) or low (as in DICE2013R), expected future annual growth is either high (2\%) or low (1\%) and climate change can be real according to the view of the scientists or non-existent according to the view of the climate deniers. Each column represents a policy optimal for the corresponding state of the world (again, damages and growth being high or low). The last column gives the case of "laissez-faire" in which carbon is not priced. Entries in Table 9 are aggregate welfare expressed as a percentage of initial world GDP (averaged across all scenarios).

Welfare under the science view is highest if the corresponding policy is implemented (i.e. in the table's main diagonal, so $892 \%$ for high growth and low damage, $891 \%$ for high growth and high damage, et cetera). Under the denier view, welfare is maximised if carbon is not priced (i.e. in the table's final column). Numbers in brackets give regret for each model across all possible policies, relative to that state's optimal policy.

In selecting the maximum among the worst possible outcome associated with each policy option, max-min policy is the most prudent of the criteria we are considering. In our case, this worst outcome is the case of low growth and high damages and thus the max-min policy is the lowgrowth and high-damage policy. Max-max policy is the optimistic counterpart to max-min policy in evaluating a policy under its best outcome. Welfare is then maximised in the case of no climate change and no climate policy, since here there are neither the cost of climate change nor of its policy. The max-max policy is thus not to price carbon at all.

The numbers in brackets in Table 9 give the regrets of conducting the wrong policies for each view of the world (again in percent of initial average GDP across all scenarios). If we include the possibility that climate change is not induced by humans, maximum regrets of each policy is dominated by the extremes of implementing climate policy needlessly and erroneously not implementing climate policy. A policy with some but not too much climate policy (low-growth high-damage) minimises regret in the numerical example of Table 9. Climate policy becomes more 
ambitious if one excludes the possibility that climate change is fake. In this case, the baseline policy of DICE (high-growth low-damages) minimises regret as it balances the costs of overdoing climate policy if damages and growth are low and the costs of unambitious policy when damages are high and expected future growth is strong.

Table 9: Aggregate welfare (in \% initial average world GDP) and relative regret (in brackets) and robust policy in the presence of damage and growth uncertainty

\begin{tabular}{|c|c|c|c|c|c|c|}
\hline \multicolumn{2}{|c|}{ state of the world } & $\begin{array}{l}\text { high growth } \\
\text { low damage }\end{array}$ & $\begin{array}{l}\text { high growth } \\
\text { high damage }\end{array}$ & $\begin{array}{l}\text { low growth } \\
\text { low damage }\end{array}$ & $\begin{array}{l}\text { low growth } \\
\text { high damage }\end{array}$ & $\begin{array}{l}\text { Don't price } \\
\text { carbon }\end{array}$ \\
\hline \multirow{2}{*}{$\begin{array}{l}\text { high growth } \\
\text { low damage }\end{array}$} & Science & $892 \% \quad(0 \%)$ & $891 \% \quad(1 \%)$ & $890 \% \quad(2 \%)$ & $892 \% \quad(1 \%)$ & $876 \% \quad(17 \%)$ \\
\hline & Denier & $909 \% \quad(8 \%)$ & $904 \%(13 \%)$ & $912 \% \quad(5 \%)$ & $909 \% \quad(8 \%)$ & $917 \%$ \\
\hline \multirow{2}{*}{$\begin{array}{l}\text { high growth } \\
\text { high damage }\end{array}$} & Science & $889 \% \quad(2 \%)$ & $891 \% \quad(0 \%)$ & $873 \%(18 \%)$ & $887 \% \quad(4 \%)$ & $701 \%(189 \%)$ \\
\hline & Denier & $909 \% \quad(8 \%)$ & $905 \%(13 \%)$ & $913 \% \quad(5 \%)$ & $909 \% \quad(8 \%)$ & $918 \%$ \\
\hline \multirow{2}{*}{$\begin{array}{l}\text { low growth } \\
\text { low damage }\end{array}$} & Science & $65 \%(2 \%)$ & $62 \%(4 \%)$ & $66 \%(0 \%)$ & $65 \% \quad(1 \%)$ & $54 \% \quad(12 \%)$ \\
\hline & Denier & $82 \%(12 \%)$ & $76 \%(17 \%)$ & $87 \% \quad(6 \%)$ & $83 \%(11 \%)$ & $94 \%$ \\
\hline \multirow{2}{*}{$\begin{array}{l}\text { low growth } \\
\text { high damage }\end{array}$} & Science & $64 \% \quad(1 \%)$ & $63 \%(2 \%)$ & $63 \%(2 \%)$ & $65 \%(0 \%)$ & $0 \% \quad(65 \%)$ \\
\hline & Denier & $83 \%(12 \%)$ & $77 \%(17 \%)$ & $88 \% \quad(6 \%)$ & $84 \%(11 \%)$ & $95 \%$ \\
\hline \multicolumn{2}{|l|}{ min welfare } & $64 \%$ & $62 \%$ & $63 \%$ & $65 \%$ & $0 \%$ \\
\hline \multicolumn{2}{|l|}{ max welfare } & $909 \%$ & $905 \%$ & $913 \%$ & $909 \%$ & $\mathbf{9 1 8 \%}$ \\
\hline \multicolumn{2}{|l|}{ max regret } & $(12 \%)$ & $(17 \%)$ & $(18 \%)$ & $(11 \%)$ & $(189 \%)$ \\
\hline \multicolumn{2}{|c|}{ max regret (excl. denier) } & $(2 \%)$ & $(4 \%)$ & $(18 \%)$ & $(4 \%)$ & $(189 \%)$ \\
\hline
\end{tabular}

Key: Aggregate welfare (rescaled and converted into \% of initial average world GDP across all scenarios) and relative regret (in brackets) for uncertainty in growth (high vs. low), damages (high vs. low), and climate change (science vs. denier). Climate policy (columns) is implemented in various states of the world (rows), e.g. the first column implements the policy optimal for a world with high growth and low damage implemented across all states of the world. Given a state of the world, relative regret captures the loss in welfare due to the implementation of a non-optimal policy. The last four rows identify max-min and max-max policies for welfare and regret.

The analysis of Table 9 can also be carried out for the case where policy makers are not concerned about welfare but about peak warming levels. Policy makers are then interested in minimising peak warming in the hottest possible state of the world for each policy. As can be seen in Table 10, peak warming levels increase if economic growth is high and the policy implemented has either low growth or damages. If policy makers strive to limit peak warming to the lowest level in the hottest 
possible outcome, they implement the most ambitious climate policy available (i.e., high-growth high-damage) corresponding to peak warming of $2.9^{\circ} \mathrm{C}$.

Table 10: Peak warming under damage and growth uncertainty

\begin{tabular}{|c|c|c|c|c|c|c|}
\hline \multicolumn{2}{|c|}{ state of the world } & $\begin{array}{l}\text { high growth } \\
\text { low damage }\end{array}$ & $\begin{array}{l}\text { high growth } \\
\text { high damage }\end{array}$ & $\begin{array}{l}\text { low growth } \\
\text { low damage }\end{array}$ & $\begin{array}{l}\text { low growth } \\
\text { high damage }\end{array}$ & $\begin{array}{c}\text { Don't price } \\
\text { carbon }\end{array}$ \\
\hline \multirow{2}{*}{$\begin{array}{l}\text { high growth } \\
\text { low damage }\end{array}$} & Science & $3.3^{\circ} \mathrm{C}$ & $2.9^{\circ} \mathrm{C}$ & $4.4^{\circ} \mathrm{C}$ & $3.5^{\circ} \mathrm{C}$ & $7.0^{\circ} \mathrm{C}$ \\
\hline & Denier & $1.4^{\circ} \mathrm{C}$ & $1.4^{\circ} \mathrm{C}$ & $1.4^{\circ} \mathrm{C}$ & $1.4^{\circ} \mathrm{C}$ & $1.4^{\circ} \mathrm{C}$ \\
\hline \multirow{2}{*}{$\begin{array}{l}\text { high growth } \\
\text { high damage }\end{array}$} & Science & $3.3^{\circ} \mathrm{C}$ & $2.9^{\circ} \mathrm{C}$ & $4.4^{\circ} \mathrm{C}$ & $3.5^{\circ} \mathrm{C}$ & $6.7^{\circ} \mathrm{C}$ \\
\hline & Denier & $1.4^{\circ} \mathrm{C}$ & $1.4^{\circ} \mathrm{C}$ & $1.4^{\circ} \mathrm{C}$ & $1.4^{\circ} \mathrm{C}$ & $1.4^{\circ} \mathrm{C}$ \\
\hline \multirow{2}{*}{$\begin{array}{l}\text { low growth } \\
\text { low damage }\end{array}$} & Science & $2.8^{\circ} \mathrm{C}$ & $2.5^{\circ} \mathrm{C}$ & $3.2^{\circ} \mathrm{C}$ & $2.8^{\circ} \mathrm{C}$ & $5.3^{\circ} \mathrm{C}$ \\
\hline & Denier & $1.4^{\circ} \mathrm{C}$ & $1.4^{\circ} \mathrm{C}$ & $1.4^{\circ} \mathrm{C}$ & $1.4^{\circ} \mathrm{C}$ & $1.4^{\circ} \mathrm{C}$ \\
\hline \multirow{2}{*}{$\begin{array}{l}\text { low growth } \\
\text { high damage }\end{array}$} & Science & $2.8^{\circ} \mathrm{C}$ & $2.5^{\circ} \mathrm{C}$ & $3.2^{\circ} \mathrm{C}$ & $2.8^{\circ} \mathrm{C}$ & $5.2^{\circ} \mathrm{C}$ \\
\hline & Denier & $1.4^{\circ} \mathrm{C}$ & $1.4^{\circ} \mathrm{C}$ & $1.4^{\circ} \mathrm{C}$ & $1.4^{\circ} \mathrm{C}$ & $1.4^{\circ} \mathrm{C}$ \\
\hline \multicolumn{2}{|c|}{ max peak warming } & $3.3^{\circ} \mathrm{C}$ & $2.9^{\circ} \mathrm{C}$ & $4.4^{\circ} \mathrm{C}$ & $3.5^{\circ} \mathrm{C}$ & $7.0^{\circ} \mathrm{C}$ \\
\hline
\end{tabular}

\section{Conclusion}

We conclude from our study of robust climate policies that the cost of avoiding the most harmful aspects of climate change is small compared with the cost of inaction, so robust policies such as doing the best under the worst possible outcomes or minimising the maximum regret call for pricing carbon to substantially curb global warming. Even for less cautious policies with finite but substantial degrees of ambiguity aversion towards climate model uncertainty and subjective prior probabilities that climate deniers are right as high as $10 \%$, the price of carbon is close to the nonsceptic, scientifically optimal one. For example, if policy makers use an ethical discount rate of $2.1 \%$ per year and private agents a discount rate of $4.4 \%$ per year, we find that the scientifically optimal carbon price of $\$ 91$ only reduced to $\$ 84$ per ton of emitted CO2. Peak warming would then only be marginally higher, namely $2.1^{\circ} \mathrm{C}$ instead of $2^{\circ} \mathrm{C}$.

Even if the subjective probability of climate deniers being right were as unbelievable high as $50 \%$, perhaps due to the partisan influence of the coal and shale gas lobbies, the carbon price would still be $\$ 51$ per ton of emitted $\mathrm{CO} 2$. In that case, peak warming would be $2.6^{\circ} \mathrm{C}$ instead of $2^{\circ} \mathrm{C}$ and the end of the fossil fuel era would be delayed by only 25 years (to 2100) relative to the rational science-based view. This delay shortens as the prior probability that deniers are right falls or 
aversion to ambiguity, about whether scientists or deniers are right, increases. Agnostic decision makers might not want to make an assessment of the prior distribution of the different views of the climate as it is fundamentally unknown. In that case, the max-min solution and thus the sciencebased policy are appropriate. This is more strongly so if marginal damages rise steeply with global warming or if policy makers place more weight on the future than private agents do.

Our study is the first to analyse the effects on the social cost of carbon of uncertainty about whether anthropogenic global warming exists or not, but there are many, scientifically relevant uncertainties that decision makers need to account for in their assessment of climate change. We can think of uncertainty about the way the world economy is modelled, uncertainty about the way the various stocks of carbon in the oceans and in the atmosphere and their effect on global mean temperature are modelled, uncertainty about the damaging effect of global warming on aggregate production, consumption, and global welfare, and uncertainty about the relevant discount rate or willingness to sacrifice consumption today for the benefit of future generations. For illustrative purpose, we have used max-min and min-regret criteria to illustrate how uncertainties about damages and economic growth interact and conclude that prudent policy makers still prefer to price carbon ambitiously rather than do no climate policy at all. This kind of analysis is informative but only a first step. Further effort is needed to make policy truly robust to known unknowns using a modular approach (NAS, 2017) and inform updating of policy as unknown unknowns become known.

Scientific uncertainties are often cited in defence of not pricing carbon, giving politicians the subterfuge to avoid painful restructuring carbon-based industries and benefitting current generations by avoiding the economic burden of climate regulation. Our results, however, discredit this wait-and-see approach. We have not set out to disprove or prove either the climate deniers' or scientific view, but have used modern decision theory to show that agnostics should strive to decarbonise the economy rapidly as the consequences of erring on the "wrong" side are too grave. The agnostic policymaker's response to climate deniers is thus strikingly simply: price carbon!

\section{References}

Ackerman, F. and E.A. Stanton (2012). Climate risks and carbon prices: revising the social cost of carbon, Economics: The Open-Access, Open-Assessment E-Journal, 6, 1-25. 
Arrow, K. and L. Hurwicz (1977). An optimality criterion for decision-making under ignorance, in Studies in Resource Allocation; Processes, Cambridge University Press, Cambridge, U.K. Arrow, K., W.R. Cline, K.-G. Mäler, M. Munasinghe, R. Squitieri and J.E. Stiglitz (1996). Intertemporal equity, discounting, and economic efficiency, Chapter 4 in Climate Change 1995 - Economic and Social Dimensions of Climate Change, Contribution of Working Group III to the Second Assessment Report, IPCC and Cambridge University Press, New York.

Bansal, R., M. Ochoa and D. Kiku (2016). Climate change and growth risks, Working Paper 23009, NBER, Cambridge, Mass.

Barrage, L. (2018). Be careful what you calibrate for: social discounting in general equilibrium, Journal of Public Economics, 160, 33-49.

Belfiori, E. (2017). Carbon pricing, carbon sequestration, and social discounting, European Economic Review, 96, 1-17.

Below, D. von (2012). Optimal carbon taxes with social and private discounting, mimeo., Oxcarre, University of Oxford.

Berger, L. and M. Marinacci (2017). Model uncertainty in climate change economics, mimeo., IGIER, Bocconi University, Milan.

Bijgaart, I.M. van den, R. Gerlagh and M. Liski (2016). A simple rule for the social cost of carbon, Journal of Environmental Economics and Management, 77, 75-94.

Bremer, T.S. van den and F. van der Ploeg (2018). The risk-adjusted carbon price, OxCarre Research Paper 203, University of Oxford.

Brock, W.A. and L. Hansen (2017). Wrestling with uncertainty in climate economic models, mimeo., University of Chicago.

Crost and Traeger (2014). Optimal CO2 mitigation under damage risk valuation, Nature Climate Change, 4, 631-636.

Dietz, S. and N. Stern (2015). Endogenous growth, convexity of damages and climate risk: how Nordhaus' framework supports deep cuts in carbon emissions. The Economic Journal 125, 583, 574-620.

Doran, P. T. and M. K. Zimmerman (2009). Examining the scientific consensus on climate change. Eos, Transactions American Geophysical Union 90, 3, 22-23.

Gilboa, I. and D. Schmeidler (1989). Maxmin expected utility with non-unique prior, Journal of Mathematical Economics 18, 141-153. 
Gollier, C. (2018). Ethical Asset Valuation and the Good Society, Columbia University Press, New York.

Golosov, M., J. Hassler and P. Krusell and A. Tsyvinski (2014). Optimal taxes on fossil fuel in general equilibrium, Econometrica, 82, 1, 48-88.

Hambel, C., H. Kraft and E. Schwartz (2017). Optimal carbon abatement in a stochastic general equilibrium model with climate change, mimeo., Frankfurt University.

Heal, G. and A. Millner (2014). Uncertainty and decision in climate change economics, Review of Environmental Policy, 8, 1, 120-137.

Hume, D. (1739). A Treatise of Human Nature, Oxford University Press, Oxford.

Hume, D. (1748). An Enquiry Concerning Human Understanding, Oxford University Press, Oxford.

Jenssen, S. and C. Traeger (2014). Optimal climate change mitigation under long-term growth uncertainty: stochastic integrated assessment and analytical findings, European Economic Review, 69, C, 104-125.

Klibanoff, P., Marinacci, M. and S. Mukerji (2005). A smooth model of decision making under ambiguity. Econometrica 73, 6, 1849-1892.

Lontzek, T.S., Y. Cai, K.L. Judd and T.M. Lenton (2015). Stochastic integrated assessment of climate tipping points indicates the need for strict climate action, Nature Climate Change, 5, 441-444.

Millner, A., Dietz, S. and G. Heal (2013). Scientific ambiguity and climate policy, Environmental and Resource Economics 55, 1, 21-46.

NAS, National Academies of Sciences, Engineering, and Medicine (2017). Valuing Climate Damages: Updating Estimation of the Social Cost of Carbon Dioxide, The National Academies Press, Washington, DC. doi: 10.17226/24651.

Nordhaus, W. (2014). Estimates of the social cost of carbon: concepts and results from the DICE2013R model and alternative approaches. Journal of the Association of Environmental and Resource Economists 1, 273-312.

Nordhaus, W. (2017). Integrated assessment models of climate change, NBER Reporter, 17, 3. http://www.nber.org/reporter/2017number3/nordhaus.html

Nordhaus, W. (2018). Projections and uncertainties about climate change in an era of minimal climate policies, American Economic Journal: Economic Policy, forthcoming. 
Pascal, B. (1670). Pensées (Translated by W.F. Trotter), London, Dent, 1910).

Pindyck, R.S. (2017). The use and misuse of models for climate policy, Review of Environmental Economics and Policy, 11, 1, 100-114.

Ploeg, F. van der (2014). Abrupt positive feedback and the social cost of carbon, European Economic Review, 67, 28-41.

Ploeg, F. van der and A.J. de Zeeuw (2018). Climate tipping and economic growth: precautionary capital and the price of carbon, Journal of the European Economic Association, forthcoming.

Rezai, A. and F. van der Ploeg (2016). Intergenerational inequality aversion, growth, and the role of damages: Occam's rule for the global carbon tax, Journal of the Association of Environmental and Resource Economists, 3, 2, 493-522.

Rezai, A. and F. van der Ploeg (2018a). Climate model uncertainty and the social cost of carbon: A modular approach, mimeo.

Rezai, A. and F. van der Ploeg (2018b). Climate policy under climate-model uncertainty: max-min and min-max regret, Energy Economics, 11, 627-639.

Savage, L.J. (1951). The theory of statistical decision, Journal of the American Statistical Association, 46, 55-67.

Savage, L.J. (1954). Foundations of Statistics, John Wiley, New York.

Schmitt, A. (2014). Optimal carbon and income taxation, mimeo, Ifo Institut, Munich.

Stern, N.H. (2007). The Economics of Climate Change: The Stern Review, Cambridge University Press, Cambridge, United Kingdom.

Stern, N. (2015). Why Are We Waiting. The Logic, Urgency, and Promise of Tackling Climate Change, The MIT Press, Cambridge, Mass.

Wald, A. (1945). Statistical decision functions which minimize the maximum risk. The Annals of Mathematics 46, 2, 265-280.

Weitzman, M. (2009). On modeling and interpreting the economics of catastrophic climate change, The Review of Economics and Statistics, XCI, 1, 1-6.

Weitzman, M. (2010). What is the "damage function" for global warming- and what difference does it make?, Climate Change Economics 1, 57-69. 


\section{Appendix: Model details and computational implementation}

In our simulations we use the DICE2013R integrated assessment model in its baseline calibration. The key ethical parameters in this model are the pure rate of time preference (1.5\% per annum) and the IIA (with the inverse of the IIA equal to 1.45). Damages to economic production are based on previous studies by Nordhaus, capturing market and non-market impacts. The remainder of the economic parameters is calibrated to the global economy with exogenous growth trajectories for total factor productivity and population. A 3-box carbon model and 2-box temperature model describe the climate dynamics. DICE2013R is a Ramsey growth model where all decisions are taken to maximise the present discounted value of aggregate utility. A social planner (or a government in the decentralised equilibrium described below) chooses a tax on carbon which

incentivises the emission of less carbon. A representative household makes the consumption/saving decision. A detailed description of the integrated assessment model DICE2013R is given in (5). Further details on the specification and calibration of the economy, especially damages, and the climate are given in the model's user manual under

http://www.econ.yale.edu/ nordhaus/homepage/documents/DICE_Manual_100413r1.pdf.

The 'science' model corresponds to the original version of the DICE2013 model. The 'denier' model amends the carbon emissions equation by setting industrial carbon emissions to zero, so that only exogenous non-industrial carbon emissions are entering the atmosphere. Hence, the climate dynamics becomes independent of the economy and the climate externality disappears. Climate change in the 'denier' model still exists with temperature peaking at $1.3^{\circ} \mathrm{C}$ due to committed warming, but it is unaffected by the anthropogenic emissions of the economy. These two models give us the baseline cases of the 'science' and 'denier' policy for Table 3.

The fundamental theorem of welfare economics that guarantees that the command optimum can be decentralised in a market economy does not necessarily hold under climate model uncertainty. We therefore need to augment the DICE2013R model by deriving and adding the decentralised equilibrium of the global economy as a constraint. The decentralised equilibrium contains the firms' static and the households' intertemporal decision problems. The optimal saving decision for the representative household has to satisfy the Euler equation 


$$
\frac{C_{t+1} / L_{t+1}}{C_{t} / L_{t}}=\left(\frac{1+r_{t+1}}{(1+\rho)^{\Delta t}}\right)^{1 / I I A}, \quad r_{t+1} \equiv(1-\delta)^{\Delta t}-1+\Delta t \varsigma_{t+1}\left(1-\frac{\left(1-\mu_{t+1}\right) \Lambda^{\prime}\left[\mu_{t+1}\right]}{1-\Omega\left[T_{t+1}^{a t m}\right]-\Lambda\left[\mu_{t}\right]}\right)
$$

This expression corresponds to the Ramsey-Keynes rule of the standard Ramsey growth model, but has been augmented to match the specifics of DICE where only output net of damages and mitigation costs are available for consumption and investment purposes. Growth of consumption per capita, $C_{t} / L_{t}$, increases in the ratio of the rate of interest, $r_{t}$, and the pure rate of time preference, $\rho$, and especially so if the IIA is small. The rate of interest is a convoluted expression to meet the different time-steps of the DICE model where annual flows are compounded to a semidecadal time scale $(\Delta t=5$ years $)$. Here $\delta$ is the annual depreciation rate, $\varsigma_{t}=\partial Y_{t} / \partial K_{t}$ is the rental rate of capital with $Y_{t}=\left(1-\Omega\left[T_{t+1}^{a t m}\right]-\Lambda\left[\mu_{t}\right]\right) F\left[K_{t}, L_{t}\right]$ usable output after mitigation cost, $\Lambda\left[\mu_{t}\right]$, and climate damage, $\Omega\left[T_{t+1}^{a t m}\right]$. The global policy maker maximises welfare, $W=\sum_{t=0}^{T}(1+\rho)^{-\Delta t} L_{t}\left[\frac{\left(C_{t} / L_{t}\right)^{1-\eta}-1}{1-\eta}\right]$, given the decentralised equilibrium. To achieve this, we add equation (A.1) as a constraint to the maximisation problem of DICE2013R. Policy makers choose a sequence of carbon prices or taxes, $\left\{\tau_{t}\right\}_{t=0}^{T}$, to maximise welfare. Since DICE has a one-to-one relationship between the share of emissions mitigated, $\mu_{t}$, and the imposed carbon price or tax, $\tau_{t}$, one can treat $\mu_{t}$ as the instrument directly.

In scenarios where optimal policy of one model is implemented in the other, we fix $\left\{\tau_{t}\right\}_{t=0}^{T}$, which computationally leaves the initial level of consumption $C_{0}$ to maximise welfare. Its optimal value will satisfy the terminal condition that the shadow value of capital has to equal zero in the terminal period. With climate model uncertainty, we solve for the initial level of consumption $C_{0}^{i}$ to maximise welfare in each state of the world $i$ and the policy time path $\left\{\tau_{t}\right\}_{t=0}^{T}$ which has to be identical across models. Hence, we solve the government's maximisation problem subject to each state of the world represented by (modified versions of) the DICE2013R model and an additional constraint imposing policy uniformity across states of the world. 